\title{
Elastosis in ERa-positive male breast cancer
}

\section{Marijn A. Vermeulen ${ }^{1}$ (D) Carolien H. M. van Deurzen ${ }^{2,3} \cdot$ A. Elise van Leeuwen-Stok ${ }^{3} \cdot$ Paul J. van Diest $^{1}$}

Received: 7 January 2020 / Revised: 7 August 2020 / Accepted: 1 September 2020 / Published online: 15 September 2020

(C) The Author(s) 2020

\begin{abstract}
In female breast cancer (BC), elastosis is strongly related to estrogen receptor alpha (ER $\alpha)$ expression. Male breast cancers almost invariably express ER $\alpha$; so, the aim of this study was to investigate elastosis frequency in invasive male BC as well as clinicopathological correlations, in comparison with females. A total of 177 male $\mathrm{BC}$ cases and 135 female $\mathrm{BC}$ cases were included, all ER $\alpha$-positive and invasive carcinoma of no special type. Elastosis on H\&E-stained slides was scored in a four-tiered system as elastosis grade (EG) 0 (no elastosis) to EG3 (high amount of elastosis). EG scores in male BC were correlated to histopathological characteristics and overall surviva and compared with female BC EG scores. Male BC showed some degree of elastosis in $26 / 117$ cases $(22.2 \%$ ) with none showing EG3, while female BC cases showed elastosis in 89/135 cases (65.9\%) with $21.5 \%$ showing EG3 $(p<0.001)$. This difference retained its significance in multivariate logistic regression. In male BC cases, no significant correlations were found between the amount of elastosis and age, grade, mitotic activity index, and PgR. In addition, no significant prognostic value of elastosis was seen. In conclusion, despite high ER $\alpha$ expression, male BC showed significantly less elastosis than female BC. Elastosis did not show clinicopathological correlations or prognostic value. Therefore, elastosis seems to be a less useful ER $\alpha$ tissue biomarker with less clinical significance in male BC compared with females, pointing towards important $\mathrm{BC}$ sex differences.
\end{abstract}

Keywords Breast cancer $\cdot$ Male $\cdot$ Elastosis $\cdot$ Estrogen receptor

\section{Introduction}

Elastic fibers are composed of two important components: elastin and small microfibrils. The precursor tropoelastin is secreted by fibroblasts, chondrocytes and smooth muscle cells, and this protein is crosslinked by one of the lysyl oxidase family members. The microfibrils are thought to function as a scaffold to facilitate this. Cross-linked aggregates form larger structures and eventually form a functional elastic fiber, providing elastic recoil to several different tissues [1]. Large aggregates of these elastic fibers in breast cancer $(\mathrm{BC})$ are called elastosis.

Marijn A. Vermeulen

M.A.Vermeulen-10@umcutrecht.nl

1 Department of Pathology, University Medical Center Utrecht, PO Box 85500, 3508GA Utrecht, The Netherlands

2 Department of Pathology, Erasmus MC Cancer Institute, Erasmus University Medical Center, Rotterdam, The Netherlands

3 BOOG Study Center/Dutch Breast Cancer Research Group, Amsterdam, The Netherlands
Elastosis is a well-known phenomenon in female $\mathrm{BC}$ and has been studied for decades. The biological background of elastosis in the breast is not well understood but it is suggested that the elastic fibers are not produced by only fibroblasts, but also by endothelial cells and neoplastic epithelial cells [2]. It can be observed in the periductal and perivascular spaces or diffusely in the tumor stroma. Shivas and Douglas categorized elastosis in 1972 into four grades with grade 0 corresponding to no elastosis and grade 3 corresponding to numerous dense aggregates of elastic fibers and found a favorable survival in female breast cancers showing a high amount of elastosis [3]. This correlation of elastosis with survival or favorable tumor characteristics such as low grade and Ki67 index has later been confirmed by different groups, although other groups could not confirm this [4-6]. Another well-known correlation is that of elastosis with expression of the estrogen receptor alpha $(E R \alpha)$. In ER $\alpha$-positive tumors, a high amount of elastosis can be found, compared with $\mathrm{ER} \alpha$-negative tumors that show less elastosis $[4,5,7]$.

An estimated 2670 men will develop BC in the USA in 2019 , which is almost $1 \%$ of the total number of estimated new breast cancer cases, making male $\mathrm{BC}$ a rare disease [8]. Previous studies have shown similarities, but certainly also 
differences between $\mathrm{BC}$ in males compared with females. For instance, there is a difference in distribution of histologic as well as molecular subtypes; men tend to present with $\mathrm{BC}$ at a higher age and present with more advanced disease at presentation compared with women [9-12]. In addition, important differences at the molecular and epigenetic level have been described [13, 14].

$\mathrm{BC}$ in males is almost invariably $\mathrm{ER} \alpha$ positive, but because of the important differences between male and female $\mathrm{BC}$, it cannot just be assumed that elastosis in male BC occurs in a similar frequency and show the same clinicopathologic correlations as in female BC. In the present study, our aim was therefore to establish the frequency of elastosis in ER $\alpha$ positive male $\mathrm{BC}$ and to correlate the degree of elastosis to clinicopathological features and prognosis in comparison with $\mathrm{ER} \alpha$-positive female $\mathrm{BC}$ cases.

\section{Materials and methods}

\section{Patient material}

Male patients with $\mathrm{ER} \alpha$-positive invasive $\mathrm{BC}$ were selected from the Dutch part of the EORTC 10085/TBCRC/BIG/ NABCG International Male Breast Cancer Program [15, 16], which was conducted as global effort to retrospectively assess tumor tissue of men diagnosed with breast cancer between 1989 and 2009. Male patients in The Netherlands were identified through the Dutch Cancer Registry. Paraffin-embedded male BC tissue was retrospectively collected by the Dutch Breast Cancer Research Group (BOOG). Archival tissue of all patients was handled according to the Dutch Code for Proper Use of Human Tissue (www.federa.org). A subgroup of this initial population was selected based on at least one available hematoxylin and eosin (H\&E)-stained slide and known ER $\alpha$ status. All patients were diagnosed with invasive carcinoma (IC) of no special type (NST, according to the $2012 \mathrm{WHO}$ ), resulting in 117 male patients, all with one available H\&E-stained slide containing tumor [17]. To match with this, one representative H\&E-stained slide was selected from all 135 female patients with ER $\alpha$-positive IC NST collected between 2017 and 2018 at the Department of Pathology of the University Medical Center Utrecht, Utrecht, The Netherlands. One slide of each tumor was chosen that showed the highest tumor content of all H\&E-stained slides. Elastosis degree was not taken into account when choosing the slide. All H\&E-stained slides contained a full cross section of the tumor.

Patient and tumor characteristics including age at diagnosis were recorded and the H\&E-stained slides were reviewed by two experienced pathologists to confirm the diagnosis and to assess the degree of elastosis. Consensus was reached in all cases. Unfortunately, sufficient data on lymph node status and presence of lymphovascular invasion was not available for the male BC cases; so, these factors could not be taken into account. The pT stage was known for most male $\mathrm{BC}$ cases. The pT stage was based on the TNM 8 classification [18]. The tumors were graded according to the modified Bloom and Richardson score [19]. ER $\alpha$, PgR, and HER2 were evaluated using immunohistochemistry and scored according to ASCOCAP guidelines [20]. ER $\alpha$ and PgR were considered positive when $>10 \%$ of the tumor cells showed positive staining. Survival data was available for male $\mathrm{BC}$ cases but not for female BC cases. Survival outcome was defined as death due to any cause. The average length of follow-up was 8.32 years.

\section{Quantification of elastosis}

Elastosis was assessed in a process resembling usual diagnostics: digital (scanned) slides were screened at a magnification of $5 \times$, and areas suspected for elastosis were additionally assessed at $10-20 \times$ for confirmation. Elastosis was quantified using a four-tiered system, according to the degree of elastosis observed on the H\&E-stained slide. This system was based on the system described by Shivas and Douglas in 1972 on elastica stains where Elastica Index 0 correlated to a total absence of elastosis, Elastica Index + to an occasional clump of tumor cells invested by a fine mantle of elastica, Elastica Index ++ to more numerous groups of tumor cells with a think surrounding zone of elastica, and Elastica Index +++ to numerous thick and dense aggregates of elastica [3]. We modified this system to fit to H\&E stains as we did not have elastica stains or tissue blocks available, but only H\&Es. One representative slide per patient was examined as described above. Elastosis can be seen as clumps of elastic fibers that appear as an acellular area, usually surrounding ducts or tumor fields, in H\&E-stained sections. This is easily distinguished by experienced pathologists from fibrosis or desmoplastic stroma, as elastosis appears as an eosinophilic to grayish area (like elastosis solaris in the skin) and appears as a well circumscribed area, and not as diffuse changes in the stroma. The areas of elastosis varied in size from approximately 0.3 to $1.2 \mathrm{~mm}$, although size was not a criterion that was used. Elastosis grade (EG) 0 corresponded to no demonstrable elastosis, EG1 corresponded to 1 to 3 single ducts or groups of tumor cells surrounded by elastosis, EG2 to 4-6 single ducts or tumor cells surrounded by elastosis, or 2-3 bigger and confluent fields of elastosis, and EG3 corresponded to $>6$ single ducts or groups of tumor cells surrounded by elastosis or $>3$ confluent fields of elastosis (Fig. 1). To validate our morphological scoring of elastosis in H\&E sections, 19 female $\mathrm{BC}$ cases with varying degree of elastosis on $\mathrm{H} \& \mathrm{E}$ were stained with an Elastica von Gieson stain: 5 cases with EG0, 4 with EG1, 5 with EG2, and 5 with EG3. 
Fig. 1 Elastosis in invasive male breast cancer, which can be identified in the H\&E staining and classified using a four-tiered system. Elastosis grade 0 : no elastosis can be seen (a), elastosis grade 1: only one small field of elastosis was found in this tumor (b), elastosis grade 2: 5 fields of elastosis were found in this tumor, of which 3 are shown in this image (c) and elastosis grade 3 : this tumor demonstrated a high amount of elastosis with a big confluent field of elastosis shown here (d)
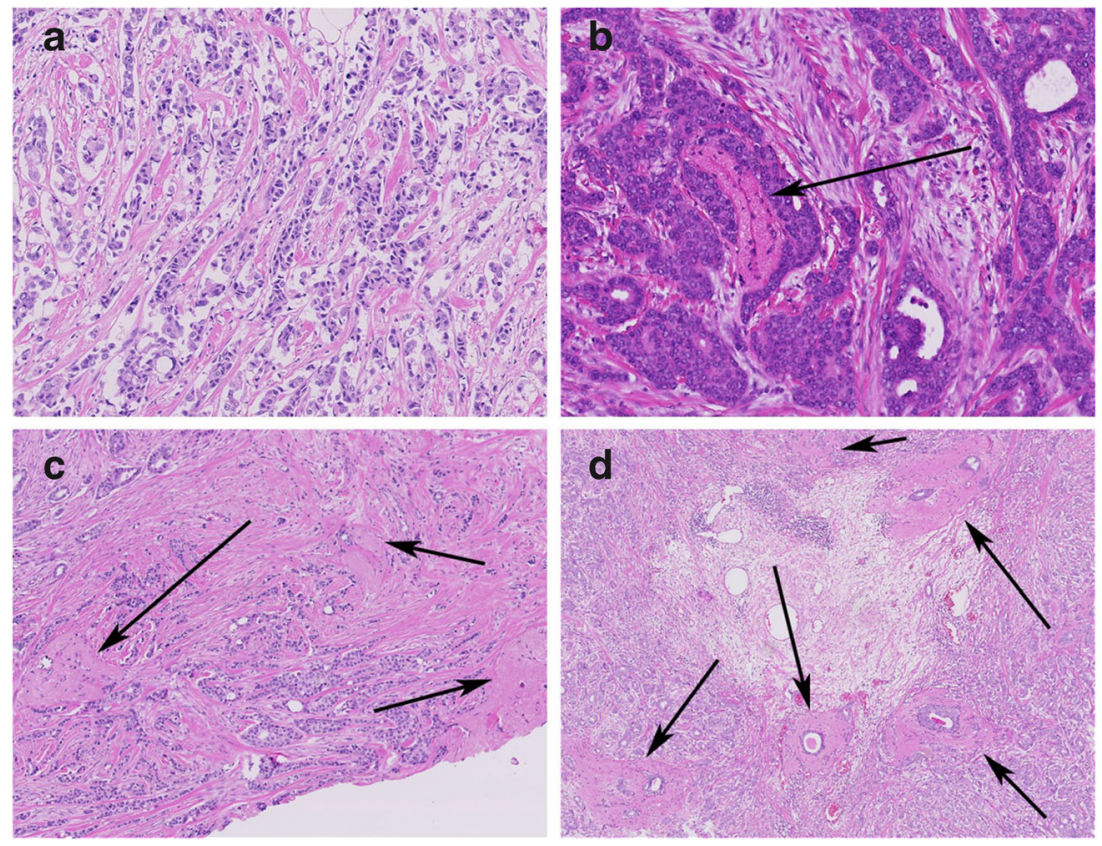

\section{Statistics}

Statistical calculations were performed using SPSS for Windows version 25. $P$ values of $<0.05$ were regarded as significant. For correlations between categorical variables, Pearson $\chi^{2}$ test (or Fisher's exact test when appropriate) was used. Continuous variables were analyzed using the $t$ test. Multivariate analysis was done with logistic regression, taking the clinicopathological features that showed significance with univariate analysis into account. Survival analysis was done by plotting a Kaplan-Meier survival curve and assessing significance with logrank test. Multivariate survival analysis was done with Cox regression.

\section{Results}

\section{Clinicopathological features}

All patients, male $(n=117)$ and female $(n=135)$, had invasive $\mathrm{BC}$ of no special type (NST) and all tumors were $\mathrm{ER} \alpha$ positive. Histopathological features of the male $\mathrm{BC}$ cases and female $\mathrm{BC}$ cases are summarized in Table 1 . The male patients had a median age of 65.4 years (28-98 years), compared with a median age of 58 years $(35-79$ years) for females $(p<0.001)$. Male BC was more frequently graded as a histologic grade $2(55.6 \%)$ compared with female BC (34.1\%), which showed a higher percentage of grade 1 and grade 3 cases $(p=0.008$ for grade 1 versus grade $2, p=0.02$ for grade 2 versus grade $3, p=0.600$ for grade 1 versus grade 3 ). The Mitotic Activity Index (MAI) was also significantly different with a lower mean MAI in male BC compared with female $\mathrm{BC}$ ( 7.45 versus 10.13 , respectively, $p=$
$0.011)$. The $\mathrm{pT}$ stage was significantly different between males and females $(p<0.001)$. In subanalysis, this difference is mainly between pT1 and pT2 $(p=0.002), \mathrm{pT} 1$ and pT4 $(p<0.001)$, pT2 and pT4 $(p<0.001)$, and pT3 and pT4 $(p=0.002)$. PgR was positive in significantly more male BC cases compared with female BC cases $(p \leq 0.001)$.

\section{Elastosis in male versus female breast cancer}

The elastosis scores for the 19 female BC cases that were stained with an Elastica von Gieson stain showed good correlation to elastosis scoring on the $\mathrm{H} \& \mathrm{E}$ slide, validating our $\mathrm{H} \& \mathrm{E}$ scoring system. In 15/19 cases, we had a perfect match between elastin stain scoring and H\&E scoring of elastosis, 3 cases were scored negative on $\mathrm{H} \& \mathrm{E}$ (EG0) but showed a tiny rim of elastosis around one duct (EG1), and 1 case was scored EG2 on H\&E but was found to have more elastosis on the elastin stain (EG3). Figure 2 illustrates this validation; Table 2 shows the data.

Table 1 shows EG scores in male and female BC. Using the four-tiered system of grading elastosis, a significant difference was found between male and female $\mathrm{BC}$. Male $\mathrm{BC}$ showed in general a lower amount of elastosis $(p<0.001)$. Male $\mathrm{BC}$ showed at least some degree of elastosis in 26/117 cases (22.2\%) with no cases showing EG3, while female BC cases showed elastosis in 89/135 cases $(65.9 \%)$ with $21.5 \%$ showing EG3 $(p<0.001)$. When comparing EG0/1 to EG2/3, significance remained $(p<0.001)$. This difference between male and female $\mathrm{BC}$ was found in subgroups of histologic grade 1 and grade 2 tumors ( $p<0.001$ for both), but not in grade 3 tumors $(p=0.199$ ).

In logistic regression considering age, MAI, grade, PgR, and elastosis (EG0/1 versus EG2/3), elastosis was the highest predictor for gender ( $p<0.001$, HR 22.487, 95\% CI 8.319-60.782). 
Table 1 Clinicopathological features of male and female breast cancer patients. Missing data were excluded in the given percentages
Table 2 Validation of elastosis scoring on Hematoxylin\&Eosin (H\&E) staining by elastic Von Gieson (EVG) staining

\begin{tabular}{|c|c|c|c|c|}
\hline \multicolumn{2}{|l|}{ Feature } & \multirow{2}{*}{$\frac{\text { Male }(n=117)}{64.4}$} & \multirow{2}{*}{$\begin{array}{l}\text { Female }(n=135) \\
58.8\end{array}$} & \multirow{2}{*}{$\frac{p \text { value }}{<0.001}$} \\
\hline Age & Mean & & & \\
\hline \multirow[t]{3}{*}{ Grade } & I & $31(26.5 \%)$ & $49(36.3 \%)$ & \multirow[t]{3}{*}{0.02} \\
\hline & II & $65(55.6 \%)$ & $46(34.1 \%)$ & \\
\hline & III & $21(17.9 \%)$ & $40(29.6 \%)$ & \\
\hline \multirow[t]{5}{*}{ pT stage } & 1 & $51(45 \%)$ & $100(75 \%)$ & \multirow[t]{5}{*}{$<0.001$} \\
\hline & 2 & $100(35 \%)$ & $31(23 \%)$ & \\
\hline & 3 & $1(1 \%)$ & $3(2 \%)$ & \\
\hline & 4 & $21(19 \%)$ & $0(0 \%)$ & \\
\hline & Missing & 5 & 1 & \\
\hline \multirow[t]{3}{*}{ Mitoses/2mm2 } & Mean & 7.45 & 10.13 & 0.011 \\
\hline & $0-8$ & $85(72.6 \%)$ & $70(51.9 \%)$ & \multirow[t]{2}{*}{0.001} \\
\hline & $>8$ & $32(27.4 \%)$ & $65(48.1 \%)$ & \\
\hline \multirow[t]{3}{*}{ PgR } & neg & $4(3.4 \%)$ & $29(21.5 \%)$ & \multirow{3}{*}{$<0.001$} \\
\hline & pos & $112(96.6 \%)$ & $106(78.5 \%)$ & \\
\hline & Missing & 1 & 0 & \\
\hline \multirow[t]{3}{*}{ HER2 } & neg & $100(89.3 \%)$ & $127(94.1 \%)$ & \multirow[t]{3}{*}{0.241} \\
\hline & pos & $12(10.7 \%)$ & $8(5.9 \%)$ & \\
\hline & Missing & 5 & 0 & \\
\hline \multirow[t]{4}{*}{ Elastosis } & 0 & $91(77.8 \%)$ & $46(34.1 \%)$ & \multirow[t]{4}{*}{$<0.001$} \\
\hline & 1 & $20(17.1 \%)$ & $32(23.7 \%)$ & \\
\hline & 2 & $6(5.1 \%)$ & $28(20.7 \%)$ & \\
\hline & 3 & 0 & $29(21.5 \%)$ & \\
\hline \multirow[t]{2}{*}{ Elastosis ( 2 categories) } & $0+1$ & $111(94.9 \%)$ & $78(57.8 \%)$ & \multirow[t]{2}{*}{$<0.001$} \\
\hline & $2+3$ & $6(5.1 \%)$ & $57(42.2 \%)$ & \\
\hline
\end{tabular}

\begin{tabular}{|c|c|c|c|}
\hline Case & Elastosis grade on $\mathrm{H} \& \mathrm{E}$ & Elastosis grade on EVG & Concordant (yes/no) \\
\hline 1 & 0 & 1 & No \\
\hline 2 & 0 & 0 & Yes \\
\hline 3 & 0 & 1 & No \\
\hline 4 & 0 & 0 & Yes \\
\hline 5 & 0 & 1 & No \\
\hline 6 & 1 & 1 & yes \\
\hline 7 & 1 & 1 & Yes \\
\hline 8 & 1 & 1 & Yes \\
\hline 9 & 1 & 1 & Yes \\
\hline 10 & 2 & 2 & Yes \\
\hline 11 & 2 & 2 & Yes \\
\hline 12 & 2 & 3 & No \\
\hline 13 & 2 & 2 & Yes \\
\hline 14 & 2 & 2 & Yes \\
\hline 15 & 3 & 3 & Yes \\
\hline 16 & 3 & 3 & Yes \\
\hline 17 & 3 & 3 & Yes \\
\hline 18 & 3 & 3 & Yes \\
\hline 19 & 3 & 3 & Yes \\
\hline \multicolumn{3}{|c|}{ Concordance } & $15 / 19(79 \%)$ \\
\hline
\end{tabular}


Fig. 2 Validation of elastosis scoring in H\&E (1) stained sections by parallel elastic staining (2) in a subset of three female breast cancer cases. a An EG0 case (on both H\&E and Elastica von Gieson (EVG) stain). b EG0 on $H \& E$ and EG1 on the EVG stain with a small rim of elastin. c An EG3 case (on both H\&E and EVG stain)
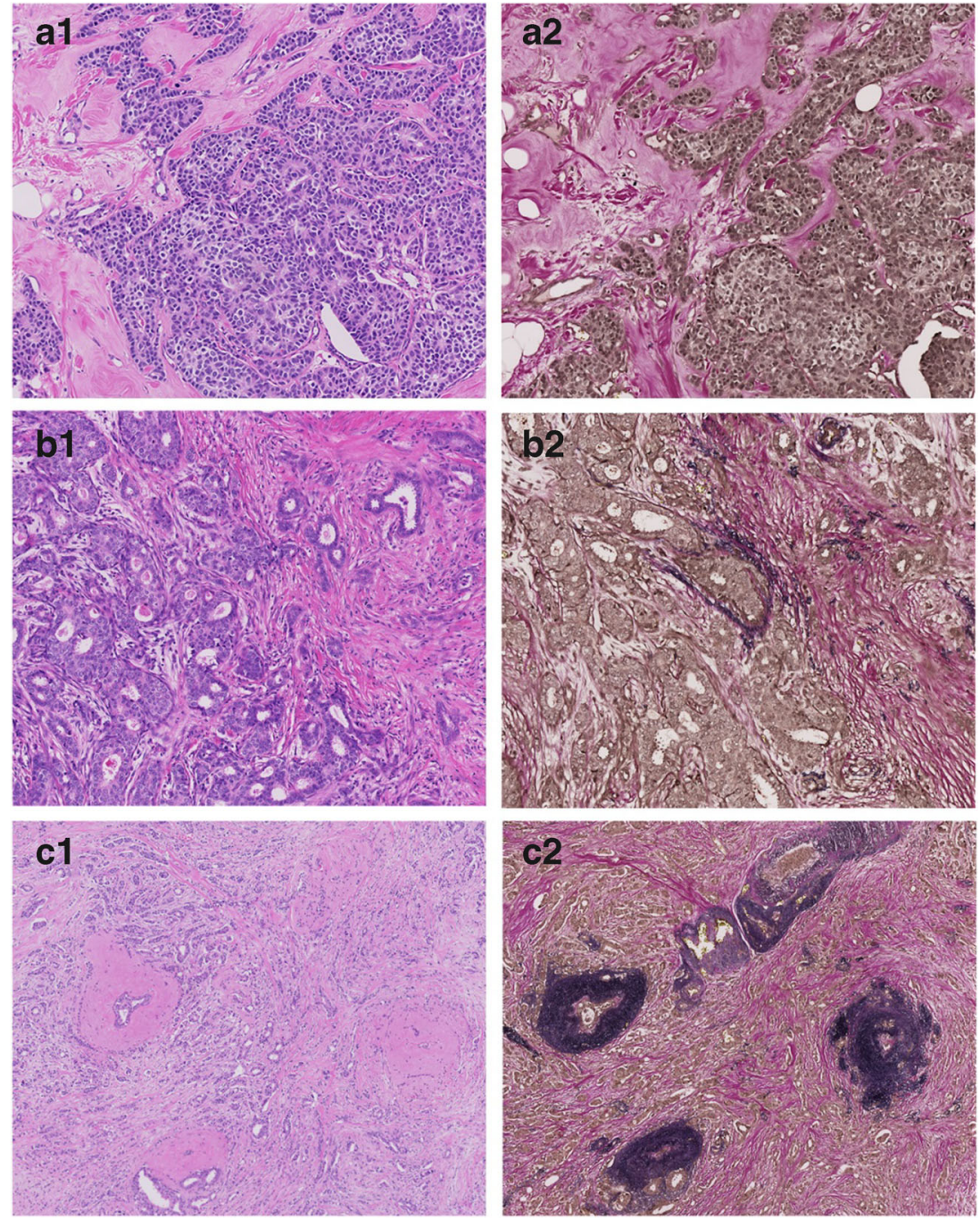

\section{Elastosis in male breast cancer: correlation with histopathological features and overall survival}

No significant differences were found between the amount of elastosis and grade $(p=0.651)$, pT stage $(p=0.331)$, age (cutoff 55 years, $p=0.276$ ) MAI (cut-off $8, p=0.613), \operatorname{PgR}(p=$ $0.834)$, or HER2 $(p=0.668)$. In univariate analysis and multivariate analysis, there was no significant difference in 10-year survival for any elastosis (EG1/2) versus no elastosis (EG0) in male BC. The Kaplan-Meier survival curve is shown in Fig. 3.

\section{Discussion}

Breast cancer is a well-known and well-studied disease as it is the leading type of cancer in women worldwide, accounting for approximately $30 \%$ of the estimated new cases of cancer in the USA in 2019 [8]. In contrast to female BC, male BC is understudied and unfamiliar among the public due to its low prevalence. Of all the breast cancers diagnosed in the USA in
2019 , only $1 \%$ occurs in the male breast [8]. When male BC is diagnosed, it is usually treated using treatment algorithms derived from female BC studies. Male BC, however, is not as similar to female $\mathrm{BC}$ as one might assume, as previous studies have shown differences in the distribution of histologic as well as molecular

Elastosis (EG 0 vs. 1/2/3)

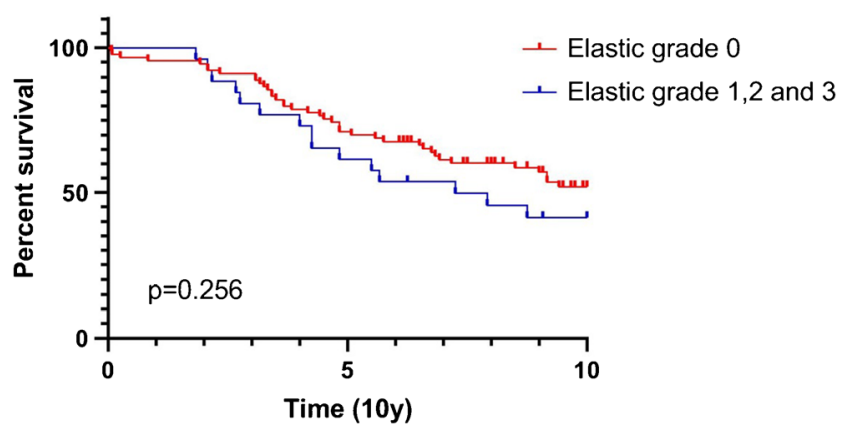

Fig. 3 Kaplan-Meier survival curves of invasive male breast cancer according to the amount of elastosis 
subtype, age at presentation, and differences at the molecular and epigenetic level [9-14].

In female $\mathrm{BC}$, it is well shown that the presence of elastosis is correlated to ER $\alpha$ expression $[4,5,7]$. To the best of our knowledge, this correlation had not been studied in male BC before. We therefore studied elastosis in 117 male $\mathrm{BC}$ cases, validated H\&E scoring by Elastica von Gieson staining in a subset of female cases, and correlated the amount of elastosis to histopathological characteristics and survival. In addition, we compared our results to 135 female $\mathrm{BC}$ cases. All cases were ER $\alpha$ positive and all cases were subtyped as invasive carcinoma of no special type, according to the WHO. The pT stage differed significantly between male and female breast cancer, mainly caused by the high number of pT4 cases in males (19\%) compared with females $(0 \%)$ and, as a result, a lower number of pT1 cases in males $(45 \%)$ compared with females $(75 \%)$. As pT4 includes cases with skin ulceration and/or chest wall invasion and these symptoms are described to be relatively frequent in males, this is a likely explanation for this finding [21].

In our study, none of the male BC cases showed an abundant amount of elastosis (EG3). Only six cases (5.1\%) showed a moderate amount of elastosis (EG2). This was significantly lower than the number of female BC cases showing EG2 and EG3 (20.7\% EG2 and 21.5\% EG3). A previous female BC study examining elastosis using a similar grading scheme (grades 0 , 1,2 , and 3 ) found $16.5 \%$ of the 272 cases to show a high amount of elastosis (EG3). A total of 33.8\% showed no elastosis (EG0), $28.7 \%$ a minimal amount (EG1), and $21.0 \%$ a moderate amount (EG2) [4]. This distribution is similar to our female BC study population and strengthens our finding that the stroma in male and female BC differs, even in multivariate analysis. A limitation of this study is that we could only examine one H\&E-stained slide of the male BC cases, and some degree of heterogeneity in the tumor cannot be excluded. To minimize the possible bias due to this issue, we also scored only one slide in the female $\mathrm{BC}$ cases for fair comparisons.

In breast cancer, the production of the elastic fibers is thought to originate from both neoplastic epithelial cells as well as from (myo-)fibroblasts [2, 3, 22, 23]. A previous study using in situ hybridization for elastin mRNA on $\mathrm{BC}$ sections and using $\mathrm{BC}$ cell lines to examine elastin biosynthesis and regulation in fibroblasts and epithelial cells showed that the regulatory mechanism of elastin biosynthesis is probably similar to the mechanism in normal elastotic fibroblasts. Cells that showed to produce immunoreactive tropoelastin were epithelial cells, fibroblasts, and endothelial cells, with usually more than one cell type involved per studied sample [2]. As the immunoreactive epithelial cells were located at the periphery and in close proximity to stroma, it is believed that the interaction between the stroma and epithelial cells triggers tropoelastin biosynthesis in the epithelial cells [2]. Other studies have also shown the importance of the stroma/ extracellular matrix $(\mathrm{ECM})$ in breast cancer $[24,25]$. That elastosis is common in $\mathrm{ER} \alpha$-positive female $\mathrm{BC}$ is a well- known fact, but the underlying mechanism of this correlation has not been described to our knowledge. As ER $\alpha$ is known to have influence on gene expression including many genes, perhaps one could speculate that in men, certain genes that play a role in elastic fiber formation are expressed differently compared with women or are more susceptible to ER influence, resulting in lower elastic fiber formation, and as a consequence, a lower amount of elastosis [26]. Why the association between ER $\alpha$ and elastosis is different in male $\mathrm{BC}$ remains an unanswered question and further research is needed. This could be investigated by looking at stromal gene signature, which has been done in a previous study revealing different signatures for different stromal elements [27].

In addition to our comparison of elastosis in male and female $\mathrm{BC}$, we correlated the amount of elastosis to different histopathological features, but no significant correlations were found between elastosis and histologic grade, pT stage, age, MAI, and PgR. The relationship between tumor size and stromal elastosis has been analyzed in a previous study by Chen et al. that found no significant correlation in female BC [4].

Also, no significant prognostic value of elastosis was seen, although a limitation of this study is that we could only use overall survival. Breast cancer-specific survival was not available. In female $\mathrm{BC}$, the correlation between survival and elastosis differs, as several studies found an improved survival in cases with a high amount of elastosis but others found no correlation or an inversed one [3-6].

In conclusion, despite high $\mathrm{ER} \alpha$ expression, male $\mathrm{BC}$ shows significantly less elastosis than female $\mathrm{BC}$ with no relevant clinicopathologic correlations or prognostic value. Therefore, elastosis seems to be a less useful ER $\alpha$ tissue biomarker with less clinical significance in male $\mathrm{BC}$ than in female $\mathrm{BC}$, again pointing towards important $\mathrm{BC}$ sex differences. Although male $\mathrm{BC}$ is a rare disease, further research is needed to better understand the underlying pathogenesis of (lack of) elastosis in male BC.

Acknowledgments We are grateful to the Dutch Breast Cancer Research Group (BOOG), the Nationwide Network and Registry of Histo- and Cytopathology in The Netherlands (PALGA), The Netherlands Cancer Registry and the Dutch Pink Ribbon.

Authors' contributions Marijn Vermeulen contributed to the study concept, design, data collection, histopathological analysis, and writing. Carolien van Deurzen and Elise van Leeuwen-Stok contributed to the patient and data collection and reviewed and edited the manuscript. Paul van Diest contributed to the study concept, design, histopathological analysis and edited and reviewed the manuscript. All authors gave final approval.

Funding This research did not receive any specific grant from any funding agency in the public, commercial, or not-for-profit sector.

\section{Compliance with ethical standards}

Conflict of interest The authors declare that they have no conflict of interest. 
Open Access This article is licensed under a Creative Commons Attribution 4.0 International License, which permits use, sharing, adaptation, distribution and reproduction in any medium or format, as long as you give appropriate credit to the original author(s) and the source, provide a link to the Creative Commons licence, and indicate if changes were made. The images or other third party material in this article are included in the article's Creative Commons licence, unless indicated otherwise in a credit line to the material. If material is not included in the article's Creative Commons licence and your intended use is not permitted by statutory regulation or exceeds the permitted use, you will need to obtain permission directly from the copyright holder. To view a copy of this licence, visit http://creativecommons.org/licenses/by/4.0/.

\section{References}

1. Wagenseil JE, Mecham RP (2007) New insights into elastic fiber assembly. Birth Defects Res C Embryo Today 81(4):229-240. https://doi.org/10.1002/bdrc.20111

2. Krishnan R, Cleary EG (1990) Elastin gene expression in elastotic human breast cancers and epithelial cell lines. Cancer Res 50(7): 2164-2171

3. Shivas AA, Douglas JG (1972) The prognostic significance of elastosis in breast carcinoma. J R Coll Surg Edinb 17(5):315-320

4. Chen Y, Klingen TA, Wik E, Aas H, Vigeland E, Liestol K, Garred O, Maehlen J, Akslen LA, Lomo J (2014) Breast cancer stromal elastosis is associated with mammography screening detection, low Ki67 expression and favourable prognosis in a population-based study. Diagn Pathol 9:230. https://doi.org/10.1186/s13000-014-0230-8

5. Rasmussen BB, Pedersen BV, Thorpe SM, Rose C (1985) Elastosis in relation to prognosis in primary breast carcinoma. Cancer Res 45(3):1428-1430

6. Robertson AJ, Brown RA, Cree IA, MacGillivray JB, Slidders W, Beck JS (1981) Prognostic value of measurement of elastosis in breast carcinoma. J Clin Pathol 34(7):738-743

7. Rasmussen BB, Rose C, Thorpe SM, Hou-Jensen K, Daehnfeldt JL, Palshof T (1981) Histopathological characteristics and oestrogen receptor content in primary breast carcinoma. Virchows Archiv A Pathol Anat Histol 390(3):347-351

8. Siegel RL, Miller KD, Jemal A (2019) Cancer statistics, 2019. CA Cancer J Clin 69(1):7-34. https://doi.org/10.3322/caac.21551

9. Giordano SH, Cohen DS, Buzdar AU, Perkins G, Hortobagyi GN (2004) Breast carcinoma in men: a population-based study. Cancer 101(1):51-57. https://doi.org/10.1002/cncr.20312

10. Ge Y, Sneige N, Eltorky MA, Wang Z, Lin E, Gong Y, Guo M (2009) Immunohistochemical characterization of subtypes of male breast carcinoma. Breast Cancer Res 11(3):R28. https://doi.org/10. $1186 /$ bcr2258

11. Kornegoor R, Verschuur-Maes AH, Buerger H, Hogenes MC, de Bruin PC, Oudejans JJ, van der Groep P, Hinrichs B, van Diest PJ (2012) Molecular subtyping of male breast cancer by immunohistochemistry. Modern Pathol 25(3):398-404. https://doi.org/10. 1038/modpathol.2011.174

12. Anderson WF, Jatoi I, Tse J, Rosenberg PS (2010) Male breast cancer: a population-based comparison with female breast cancer. J Clin Oncol 28(2):232-239. https://doi.org/10.1200/jco.2009.23.8162

13. Kornegoor R, Moelans CB, Verschuur-Maes AH, Hogenes M, de Bruin PC, Oudejans JJ, van Diest PJ (2012) Promoter hypermethylation in male breast cancer: analysis by multiplex ligationdependent probe amplification. Breast Cancer Res 14(4):R101. https://doi.org/10.1186/bcr3220

14. Kornegoor R, Moelans CB, Verschuur-Maes AH, Hogenes MC, de Bruin PC, Oudejans JJ, Marchionni L, van Diest PJ (2012)
Oncogene amplification in male breast cancer: analysis by multiplex ligation-dependent probe amplification. Breast Cancer Res Treat 135(1):49-58. https://doi.org/10.1007/s10549-012-2051-3

15. Cardoso F, Bartlett JMS, Slaets L, van Deurzen CHM, van LeeuwenStok E, Porter P, Linderholm B, Hedenfalk I, Schroder C, Martens J, Bayani J, van Asperen C, Murray M, Hudis C, Middleton L, Vermeij J, Punie K, Fraser J, Nowaczyk M, Rubio IT, Aebi S, Kelly C, Ruddy KJ, Winer E, Nilsson C, Dal Lago L, Korde L, Benstead K, Bogler O, Goulioti T, Peric A, Litiere S, Aalders KC, Poncet C, Tryfonidis K, Giordano SH (2018) Characterization of male breast cancer: results of the EORTC 10085/TBCRC/BIG/NABCG International Male Breast Cancer Program. Ann Oncol 29(2):405-417. https://doi.org/10.1093/ annonc/mdx651

16. Vermeulen MA, Slaets L, Cardoso F, Giordano SH, Tryfonidis K, van Diest PJ, Dijkstra NH, Schroder CP, van Asperen CJ, Linderholm B, Benstead K, Foekens R, Martens JW, Bartlett JM, van Deurzen CH (2017) Pathological characterisation of male breast cancer: results of the EORTC 10085/TBCRC/BIG/NABCG International Male Breast Cancer Program. Eur J Cancer (Oxford, England : 1990). https://doi. org/10.1016/j.ejca.2017.01.034

17. Lakhani SR, Ellis IO, Schnitt SJ, Tan PH, van de Vijver MJ (2012) WHO Classification of Tumours of the Breast. Fourth Edition

18. Giuliano AE, Connolly JL, Edge SB, Mittendorf EA, Rugo HS, Solin LJ, Weaver DL, Winchester DJ, Hortobagyi GN (2017) Breast cancer-major changes in the American Joint Committee on Cancer eighth edition cancer staging manual. CA Cancer J Clin 67(4):290-303. https://doi.org/10.3322/caac.21393

19. Elston CW, Ellis IO (1991) Pathological prognostic factors in breast cancer. I The value of histological grade in breast cancer: experience from a large study with long-term follow-up. Histopathology 19(5):403-410

20. Wolff AC, Hammond ME, Hicks DG, Dowsett M, McShane LM, Allison KH, Allred DC, Bartlett JM, Bilous M, Fitzgibbons P, Hanna W, Jenkins RB, Mangu PB, Paik S, Perez EA, Press MF, Spears PA, Vance GH, Viale G, Hayes DF (2013) Recommendations for human epidermal growth factor receptor 2 testing in breast cancer: American Society of Clinical Oncology/College of American Pathologists clinical practice guideline update. J Clin Oncol 31(31):3997-4013. https://doi. org/10.1200/jco.2013.50.9984

21. Borgen PI, Wong GY, Vlamis V, Potter C, Hoffmann B, Kinne DW, Osborne MP, McKinnon WM (1992) Current management of male breast cancer. A review of 104 cases. Ann Surg 215(5): 451-457; discussion 457-459. https://doi.org/10.1097/00000658199205000-00007

22. Martinez-Hernandez A, Francis DJ, Silverberg SG (1977) Elastosis and other stromal reactions in benign and malignant breast tissue: an ultrastructural study. Cancer 40(2):600-606

23. Parfrey NA, Doyle CT (1985) Elastosis in benign and malignant breast disease. Hum Pathol 16(7):674-676

24. Soysal SD, Tzankov A, Muenst SE (2015) Role of the tumor microenvironment in breast cancer. Pathobiology 82(3-4):142-152. https://doi.org/10.1159/000430499

25. Giussani M, Merlino G, Cappelletti V, Tagliabue E, Daidone MG (2015) Tumor-extracellular matrix interactions: identification of tools associated with breast cancer progression. Semin Cancer Biol 35:3-10. https://doi.org/10.1016/j.semcancer.2015.09.012

26. Zheng Y, Shao X, Huang Y, Shi L, Chen B, Wang X, Yang H, Chen Z, Zhang X (2016) Role of estrogen receptor in breast cancer cell gene expression. Mol Med Rep 13(5):4046-4050. https://doi. org $/ 10.3892 / \mathrm{mmr} .2016 .5018$

27. Winslow S, Leandersson K, Edsjo A, Larsson C (2015) Prognostic stromal gene signatures in breast cancer. Breast Cancer Res 17:23. https://doi.org/10.1186/s13058-015-0530-2

Publisher's note Springer Nature remains neutral with regard to jurisdictional claims in published maps and institutional affiliations. 